\title{
Association Between Chocolate Consumption and Severity of First Infarction
}

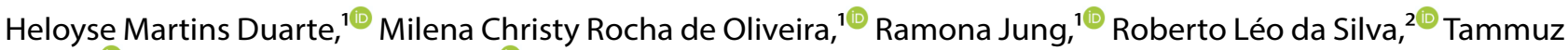 \\ Fatah, $^{2}$ Daniel Medeiros Moreira ${ }^{1,2}$

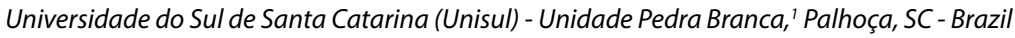 \\ Instituto de Cardiologia de Santa Catarina (ICSC)² - São José, SC - Brazil
}

\section{Abstract}

Background: Cardiovascular diseases, such as acute myocardial infarction, are the main causes of death in the world. The flavonoids present in chocolate can have benefits for people who have risk factors to the development of cardiovascular diseases and have a coadjuvant effect on known therapies.

Objective: To analyze the association between chocolate consumption, severity of coronary lesions, risk factors and severity of the first infarction in patients attended at the Cardiology Institute of Santa Catarina and other hospitals in the State of Santa Catarina.

Methods: Subanalysis of the Catarina Heart Study cohort, evaluated 350 patients with first myocardial infarction. We evaluated clinical, echocardiographic, hemodynamic laboratorial variables. We used chi square test to evaluate qualitative variables, $\mathrm{t}$ student test in the case of parametric variables and U Mann Whitney test in non-parametric variables. We considered significant $\mathrm{p}<0,05$.

Results: Lower prevalence of hypertension $(43.2 \% \%$ vs. $62.3 \% \mathrm{p}=0.003)$, diabetes mellitus $(13.5 \%$ vs. $25.7 \%$, $\mathrm{p}=0.027)$ and smoking $(24.3 \%$ vs. $37.7 \%, \mathrm{p}=0.032)$ among those who consume chocolate. Higher use of alcohol $(40.5 \%$ vs. $26.4 \%, \mathrm{p}=0.018)$ and drugs $(9.5 \%$ vs. $3.3 \%, \mathrm{p}=0.023)$ among those who consumed chocolate. Among the patients who consumed chocolate, there was a negative correlation between amount consumed and Syntax $(\mathrm{r}=-0.296, \mathrm{p}=0.019)$.

Conclusion: There was association between chocolate consumption and lower prevalence of hypertension, diabetes and smoking. There was no association between amount of chocolate consumed and post-infarction ventricular function and TIMI frame count. Higher prevalence of alcohol and drug use among those who consume chocolate. Negative correlation between Syntax and the amount of chocolate consumed. (Int J Cardiovasc Sci. 2019;32(6):576-582)

Keywords: Cardiovascular Diseases/mortality; Myocardial Infarction/physiopathology; Flavonoids; Polyphenols; Cacao.

\section{Introduction}

Cardiovascular diseases (CVD) are the leading cause of death worldwide. ${ }^{1}$ These include acute myocardial infarction (AMI) which, from 2008 to 2017, accounted for 813,982 hospital admissions in Brazil. ${ }^{2}$

There is evidence of the link between reduction of risks of cardiovascular events and chocolate consumption in larger amounts, as chocolate contains flavonoids. ${ }^{3,4}$
Studies indicate that flavonoids present in cocoa or cocoa products have the potential to benefit people with risk factors for the development of CVD through different mechanisms, such as anti-inflammatory action..$^{5-8}$ This is of great importance, as AMI is also characterized as an inflammatory disease. ${ }^{9}$

However, aspirin and statins are the only medications that fight inflammation and are used in AMI. ${ }^{9}$ The inclusion of a relatively high amount of high-flavonoid 
cocoa in the daily diet could reduce cardiovascular outcomes, make them less severe and improving the prognosis of patients after an AMI episode.

Chocolate, whose composition is rich in flavonoids, may have an adjuvant effect to ischemic disease therapies, mainly due to the anti-inflammatory action..$^{5-7}$ However, although there are indications that chocolate may decrease the occurrence of AMI events, there is no evidence that it may be associated with lower complexity of coronary lesions in patients with AMI or that AMI may be less severe. This study analyzes the association between chocolate consumption and the complexity of coronary lesions, as well as the risk factors for cardiovascular outcomes and the severity of first infarction.

\section{Methods}

This study is a subanalysis of the Catarina Heart Study ${ }^{10}$ - a prospective cohort study that began in July 2016 that is intended to evaluate 1,426 patients by the year 2020 and proposes a follow-up of thirty days and one year. The patients selected were diagnosed as having the first AMI and were assisted at the Cardiology Institute of Santa Catarina and other hospitals in the State of Santa Catarina. Once the patients' consent was taken, they answered a questionnaire that included different clinical, laboratory, electrocardiographic, echocardiographic and angiographic variables from July 2016 to July 2018.

Inclusion criteria were minimum 18 years of age, presence of precordial pain suggestive of AMI associated with electrocardiogram with new ST-segment elevation at point $\mathrm{J}$ in two contiguous leads with $\geq 0.1 \mathrm{mv}$ limits on all leads, in addition to the V2-V3 leads in which the following limits apply: $\geq 0.2 \mathrm{mv}$ in men $\geq 40$ years of age; $\geq 0.25 \mathrm{mv}$ in men $<40$ years of age, or $\geq 0.15 \mathrm{mV}$ in women or the presence of precordial pain suggestive of AMI associated with elevation of troponin I or CK-MB above the $99^{\text {th }}$ percentile of the upper reference limit. Exclusion criterion was the presence of previous AMI.

The primary endpoint of this study evaluated the association between chocolate consumption with severity, complexity and AMI complications. Secondary outcomes assessed the association between chocolate consumption and prevalence of classic cardiovascular risk factors and the correlation between chocolate consumption and variables associated with the complexity of coronary lesions and severity of infarction in patients who ate chocolate.
Measurement of chocolate consumption was done by asking the patients whether they had chocolate or not and the number of chocolate bites eaten per week. 43 grams were used as standard for each bite eaten, and the total consumption per week was divided by the days in order to evaluate the average consumption in grams per day.

To assess the severity and complexity of AMI, three variables were used: Syntax, Thrombolysis in Myocardial Infarction (TIMI) frame count and Left Ventricular Ejection Fraction (LVEF). The first variable is a score that considers the location, quantity and the respective repercussion of the lesions in the functioning of the coronary arteries, and the higher the Syntax index, the greater the complexity of coronary lesions. ${ }^{11}$ The TIMI frame count evaluates the number of film frames from the beginning of the contrast injection to the range of the coronary artery end. It is an estimate of arterial perfusion performed after therapeutic management. ${ }^{12}$ This variable was only applied for patients with AMI with STsegment elevation. LVEF was estimated by transthoracic echocardiography within 72 hours after AMI.

Hypertension, diabetes mellitus and dyslipidemia were self-reported at the time of the study. Chocolate consumption was considered positive in those who ate it regularly, at least once a week. Patients with a positive family history were considered those who had firstdegree relatives with coronary artery disease, women $\leq 65$ years old and men $\leq 55$ years old. Regarding the use of drugs and alcohol, any consumption of these substances was considered positive. As for relevant smoking, consumption of any tobacco at the time of the interview.

\section{Statistical analysis}

The current study sample was calculated as 158 patients with a power of $90 \%$ and alpha $=0.05$ for a correlation of 0.35 between the consumption of chocolate per day in grams. Data were organized into a table and analyzed by the software SPSS 13.0. The qualitative variables were expressed using absolute and percentage numbers and evaluated using the chi-square test. Quantitative variables with normal distribution were presented as mean \pm standard deviation and were evaluated using Student's t-test for independent samples, while quantitative variables with non-normal distribution were presented as median and interquartile range and were evaluated using Mann-Whitney's U test. Normality was evaluated using the Kolmogorov-Smirnov test. Among patients who consumed chocolate, the amount in grams 
per day was correlated with the variables of AMI severity using Spearman's correlation. In this study, $\mathrm{p}<0.05$ was considered statistically significant.

The Catarina Heart Study was submitted to the Research Ethics Committee of Instituto de Cardiologia de Santa Catarina pursuant to Resolution 466/12, under the protocol 55450816.0.1001.0113. The patients were informed about the secrecy of the information collected in the questionnaire, and signed a consent form before applying the questionnaire.

\section{Results}

From July 2016 to July 2018, 350 patients aged 59.0 \pm 11.0 years were evaluated. Most patients were males (64.0\%) and hypertensive (58.3\%). Regarding chocolate, $21.1 \%$ of the patients consumed it regularly, while Syntax presented a median value of $12.0(6.0-19.0)$. The prevalence of diabetes mellitus in the interviewed population was $23.1 \%$ and the diagnosis of infarction with ST-segment elevation was delivered in 169 patients (48.0\%). Median chocolate consumption among those who had chocolate was 21.5 grams per day. The other variables are presented in Table 1.

The study showed an association between chocolate consumption and the absence of systemic arterial hypertension: $43.2 \%$ of the patients who consumed chocolate were hypertensive, while $62.3 \%$ of those who did not eat the food had hypertension $(\mathrm{p}=0.003)$. Likewise, there is a significant association between absence of diabetes mellitus and consumption of chocolate: $13.5 \%$ of patients who consume chocolate have the disease, while $25.7 \%$ of those who do not eat chocolate have diabetes, with $\mathrm{p}=0.027$. There was a higher prevalence of smokers among patients who did not consume chocolate $(37.7 \%)$ compared to those who consumed chocolate $(24.3 \%)$, with $\mathrm{p}=0.032$.

In addition, there was greater consumption of alcoholic beverages among those who consume chocolate (40.5\%) compared to those who do not consume chocolate $(26.4 \%)$, with $\mathrm{p}=0.018$. The group that used drugs was bigger among those who consumed chocolate (9.5\%), compared to those who do not consume chocolate $(3.3 \%)$, with $\mathrm{p}=0.023$. Dyslipidemia and family history of cardiovascular diseases were not associated with chocolate consumption. (Table 2).

\begin{tabular}{lc}
$\begin{array}{l}\text { Table } 1 \text { - Demographic, clinical and lifestyle } \\
\text { characteristics of the study population }\end{array}$ \\
\hline Variables \\
\hline Male sex - N (\%) \\
Hypertension - N (\%) \\
Diabetes mellitus - N (\%) \\
Dyslipidemia - N (\%) & $204(58.3)$ \\
Family history - N (\%) & $81(23.1)$ \\
Smoking - N (\%) & $120(34.4)$ \\
Alcohol - N (\%) & $153(43.7)$ \\
Chocolate consumption - N (\%) & $122(34.9)$ \\
ST-segment elevation infarction - N (\%) & $103(29.4)$ \\
Age* & $74(21.1)$ \\
Body mass index* & $39(50.6)$ \\
Waist* & $59.0 \pm 11.0$ \\
Weight - median (AIQ) & $27.6 \pm 5.0$ \\
Chocolatet - median (AIQ) & $95.5 \pm 13.8$ \\
Syntax - median (AIQ) & $74.0(65.0-83.0)$ \\
TIMI frame - median (AIQ) & $21.5(6.1-56.8)$ \\
\hline$*=$ Mean \pm standard deviation, $+=$ Chocolate grams per day, only \\
among those who consume chocolate. \\
\hline
\end{tabular}

Table 2 - Association between chocolate consumption and risk factors

\begin{tabular}{|c|c|c|c|}
\hline \multirow{3}{*}{ Variables } & \multicolumn{2}{|c|}{ Chocolate consumption } & \multirow{3}{*}{ p value } \\
\hline & Yes & No & \\
\hline & n (\%) & n (\%) & \\
\hline Hypertension & $32(43.2)$ & $172(62.3)$ & 0.003 \\
\hline Diabetes mellitus & $10(13.5)$ & $71(25.7)$ & 0.027 \\
\hline Dyslipidemia & $23(31.1)$ & $97(35.3)$ & 0.500 \\
\hline Family history & $39(52.7)$ & $114(41.3)$ & 0.079 \\
\hline Smoking & $18(24.3)$ & $104(37.7)$ & 0.032 \\
\hline Alcohol & $30(40.5)$ & $73(26.4)$ & 0.018 \\
\hline Drugs & $7(9.5)$ & $9(3.3)$ & 0.023 \\
\hline
\end{tabular}


The mean LVEF among those who consumed chocolate $(48.7 \pm 15.3)$ did not present any significant difference to those who did not consume chocolate $(51.2 \pm 13.0)$, with $\mathrm{p}=0.228$. The other variables are presented in Table 3 .

Among the patients who consumed chocolate, there was a negative correlation between the amount consumed and Syntax $(r=-0.296, p=0.019)$, characterizing a lower complexity of coronary lesions in patients consuming more chocolate. (Table 4).

\section{Discussion}

This study analyzed the complexity of coronary lesions and the severity of the first infarction with chocolate consumption. The data showed that, among patients who consume chocolate, there is a negative correlation between Syntax and the amount consumed, characterizing lower

\begin{tabular}{|c|c|c|c|}
\hline \multirow{2}{*}{ Variables } & \multicolumn{2}{|c|}{ Chocolate consumption } & \multirow{2}{*}{ p value } \\
\hline & Yes & No & \\
\hline Age $^{*}$ & $58.5 \pm 11.6$ & $59.2 \pm 10.9$ & 0.639 \\
\hline $\mathrm{BMI}^{*}$ & $27.9 \pm 4.7$ & $27.6 \pm 5.1$ & 0.624 \\
\hline Waist $^{*}$ & $97.4 \pm 14.8$ & $95.0 \pm 13.5$ & 0.202 \\
\hline $\mathrm{LVEF}^{*}$ & $48.7 \pm 15.3$ & $51.2 \pm 13.0$ & 0.228 \\
\hline Weight† & $74(64.0-86.0)$ & $74(65.0-82.0)$ & 0.386 \\
\hline Syntaxt & $14(6.8-18.6)$ & $11(6.0-19.0)$ & 0.778 \\
\hline TIMI frame† & $28(12.0-48.0)$ & $20(14.0-32.5)$ & 0.360 \\
\hline \multicolumn{4}{|c|}{$\begin{array}{l}*=\text { Mean } \pm \text { standard deviation, } t=\text { Median (Interquartile range); BMI: } \\
\text { Body mass index; FEVE: Left ventricular ejection fraction. }\end{array}$} \\
\hline
\end{tabular}

Table 4 - Correlation between chocolate consumption and variables associated with coronary complexity and severity of infarction in patients who had chocolate

\begin{tabular}{lcc}
\hline Variables & $\mathbf{r}$ & p value \\
\hline LVEF $^{*}$ & -0.070 & 0.613 \\
TIMI frame & 0.131 & 0.499 \\
Syntax & -0.296 & 0.019 \\
\hline$*$ * Left ventricular ejection fraction. & \\
\hline
\end{tabular}

severity of coronary lesion in patients who had chocolate in larger amounts. In addition, there was a lower prevalence of hypertension, diabetes and smoking among those who consumed chocolate.

Similarities were found in the literature regarding the profile of the interviewed population, with a higher prevalence of males in patients affected by AMI. ${ }^{13-17}$ In addition, it was found that most of these patients had hypertension as a risk factor for the cardiovascular event ${ }^{13-16}$. Regarding smoking, less than half of the population interviewed had this addiction, as also found in other publications. ${ }^{14,15,17}$

There was a lower prevalence of hypertension among those who consumed chocolate. This relationship has also been found in several other studies, which have shown reduced blood pressure with consumption of flavonoids,

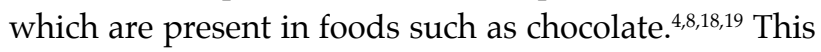
association can be justified by the fact that flavonoids would improve endothelial function, since endothelial dysfunction is associated with hypertrophy and arterial wall stiffening. ${ }^{18,20,21}$ One of the mechanisms of endothelial function improvement is the increased bioavailability of nitric oxide from the consumption of flavonoids, which results in a vasodilator effect and increases blood flow in the vessels, with consequent reduction in blood pressure levels., ${ }^{22,23}$ Another important route of the benefits of flavonoids in reducing blood pressure is the inhibition of the angiotensin converting enzyme activity, as the formation of angiotensin II results in vasoconstriction and increased blood pressure, which increases the risk of cardiovascular outcomes..$^{23,24}$

An association was also found between the use of alcohol and drugs with chocolate consumption, and a higher prevalence of consumption of these substances among patients have drink chocolate on a weekly basis. Some studies justify this relationship by the addictive characteristics of chocolate, which has compounds that can cause addiction, as in other substances, such as alcohol and other drugs. ${ }^{25,26}$ Moreover, chocolate addiction also includes the typical stages of alcoholism and other drug addictions, such as relapse. At this stage, the individual goes back to having chocolate compulsively, without thinking about the adverse effects of exaggerated consumption, which further corroborates the additive effect of chocolate, which may prevail in those who are prone to addictive behaviors. ${ }^{27}$ Another relevant point is that drugs, such as marijuana, are appetite stimulants, so they can increase the consumption of foods, including chocolate..$^{28,29}$ 
There was also an association between chocolate consumption and lower prevalence of smoking, but this finding only seems to be coincidental.

An association between chocolate consumption and diabetes mellitus was also found. Studies suggest an inverse relationship between the prevalence of diabetes mellitus and chocolate intake. ${ }^{8,30-33}$ Research studies have found that one of the mechanisms of this inverse relationship between chocolate and diabetes mellitus is the increased sensitivity to insulin caused by flavonoids, which helps to reduce blood glucose in the stream and can delay the onset of the disease. ${ }^{34,35}$ An important point, reported in one of the studies analyzed, is that flavonoid consumption as a protective effect of diabetes mellitus should be recommended with caution. This is relevant because the study argues that large amounts of sugars and calories can be found in a number of cocoa products rather than high flavonoid content, which can generate a rebound effect, worsening the glycemic control of patients with type 2 diabetes mellitus. ${ }^{36}$ Some authors believe that the beneficial effect of flavonoids also occurs in patients who already have established diabetes mellitus, reducing the risk of cardiovascular outcomes in these individuals, such as AMI. ${ }^{19,20}$ However, it is relevant to express that patients who already have diabetes mellitus are advised not to consume sugars and, in this study, the patients interviewed already had the disease and, therefore, should eat less chocolate.

Among the patients who consumed chocolate, there was a negative correlation between Syntax and the amount of chocolate consumption. The median chocolate consumption among the patients was 21.5 grams per day. There is evidence that a daily dose of $80 \mathrm{mg}$ could promote beneficial vascular outcomes. ${ }^{18}$ There is also data showing an immediate improvement in coronary flow after consumption of 45 grams of chocolate with high cocoa content. ${ }^{37}$ The correlation between higher amount of chocolate consumption and lower complexity of coronary lesions may be justified by the anti-inflammatory properties of the flavonoids present in chocolate. ${ }^{5-7}$ Another important mechanism is the antioxidant action of flavonoids, which helps reducing free radicals and may result in coronary lesions of lower severity. ${ }^{7,38}$ Also, a recent clinical trial has shown that chocolate with high cocoa content improves endothelial function (assessed through flow-mediated vasodilatation of the brachial artery) in patients with established coronary artery disease..$^{39}$ In addition to that, the beneficial effects of chocolate consumption are associated with lower mortality due to cardiovascular outcomes, which suggests lower severity of AMI in those who consume chocolate in higher amounts. ${ }^{8,40}$ However, it was not possible to establish the exact amount of recommended consumption in order to reduce the severity of the cardiovascular outcome. It is worth noting that, although there was a negative correlation between the complexity of coronary lesions and the amount of chocolate consumed, there was no association between the amount consumed and other variables associated with severity, such as post-infarction ventricular function (LVEF) and coronary flow after primary angioplasty (TIMI frame count).

Regarding the limitations of this study, the comorbidities of patients and the risk factors for cardiovascular outcomes were evaluated at a single moment, which may compromise the cause-effect relationship. Variables such as alcoholism and smoking were self-reported, which could underestimate their prevalence. Also, some risk factors such as prior coronary artery bypass grafting or kidney disease requiring dialysis were not exclusion criteria and could influence the outcomes: however, the prevalence of these variables was less than $1 \%$ (data not shown). Type I error may have occurred in some findings, such as the association between chocolate consumption and lower prevalence of smoking. It was not possible to measure the proportion of cocoa present in the chocolate consumed. Another limitation of the study was the lack of income evaluation, since there could be a bias of contamination, since higher consumers of chocolate could be those with higher incomes and greater access to health services, even though the evaluation was performed exclusively in public hospitals. Besides, most patients interviewed were from a single hospital. These biases, however, do not invalidate the data found: literature data on the subject are still scarce and this evidence justifies new research studies such as clinical trials designed with adequate power to evaluate the association between chocolate consumption in patients with ischemic heart disease and the reduction of outcomes such as mortality.

\section{Conclusion}

There was an inverse association between chocolate consumption and hypertension, diabetes mellitus and smoking. There was also an association between 
chocolate consumption and higher prevalence of drug and alcohol use. There was no association between the amount of chocolate consumed and post-infarction ventricular function (LVEF) and coronary flow after TIMI frame count. There was also a negative correlation between Syntax and the amount of chocolate consumed, suggesting lower severity of coronary lesion in patients who consumed chocolate in larger amounts.

\section{Author contributions}

Conception and design of the research: Duarte HM, Moreira DM, Silva RL, Fattah T. Acquisition of data: Duarte HM, Moreira DM, Silva RL, Fattah T. Analysis and interpretation of the data: Duarte HM, Moreira DM, Silva RL, Fattah T. Statistical analysis: Duarte HM, Moreira DM. Writing of the manuscript: Duarte HM, Moreira DM, Oliveira MCR, Jung R. Critical revision of the manuscript for intellectual content: Duarte HM, Moreira DM, Oliveira MCR, Jung R.

\section{Potential Conflict of Interest}

No potential conflict of interest relevant to this article was reported.

\section{Sources of Funding}

There were no external funding sources for this study.

\section{Study Association}

This article is part of the thesis of work of course conclusion submitted by Heloyse Martins Duarte, from Universidade do Sul de Santa Catarina (Unisul).

\section{Ethics approval and consent to participate}

This study was approved by the Ethics Committee of the Instituto de Cardiologia de Santa Catarina (ICSC) under the protocol number 55450816010010113. All the procedures in this study were in accordance with the 1975 Helsinki Declaration, updated in 2013. Informed consent was obtained from all participants included in the study.

\section{References}

1. GBD 2013 Mortality and Causes of Death Collaborators. Global, regional, and national age-sex specific all-cause and cause-specific mortality for 240 causes of death, 1990-2013: a systematic analysis for the Global Burden of Disease Study 2013. Lancet. 2015;385(9963):117-71.

2. Brasil. Ministério da Saúde. Departamento de Informática do Sistema Único de Saúde (SUS). Internações por Infarto Agudo do Miocárdio - por Região/Unidade de Federação e Ano atendimento - Brasil. [citado 07 set 2017]; Disponível em: http: / / tabnet.datasus.gov.br/cgi/deftohtm. exe?sih/cnv/niuf.def.

3. Kwok CS, Boekholdt SM, Lentjes MA, Loke YK, Luben RN, Yeong JK, et al. Habitual chocolate consumption and risk of cardiovascular disease among healthy men and women. Heart. 2015;101(16):1279-87.

4. Larsson SC, Åkesson A, Gigante B, Wolk A. Chocolate consumption and risk of myocardial infarction: a prospective study and meta-analysis. Heart. 2016;102(13):1017-22.

5. Martín MA, Ramos S. Cocoa polyphenols in oxidative stress: potential health implications. J Funct Foods. 2016 Dec;27:570-88.

6. Sarriá B, Martínez-López S, Sierra-Cinos JL, Garcia-Diz L, Goya L, Mateos $\mathrm{R}$, et al. Effects of bioactive constituents in functional cocoa products on cardiovascular health in humans. Food Chem. 2015 May 1;174:214-8.

7. Siedentopp U. Cacao - precious protector for heart and blood vessels. Rev Int Acupuntura. 2009;3(4):197-200.

8. Otto CM. Heartbeat: chocolate and atrial fibrillation. Heart. 2017;103(15):1139-40.

9. Moreira DM, da Silva RL, Vieira JL, Fattah T, Lueneberg ME, Gottschall CA. Role of vascular inflammation in coronary artery disease: potential of anti-inflammatory drugs in the prevention of atherothrombosis. Inflammation and anti-inflammatory drugs in coronary artery disease. Am J Cardiovasc Drugs. 2015;15(1):1-11.

10. Medicine, U.S.N.L.o. Post-Myocardial Infarction Patients in Santa Catarina, Brazil - Catarina Heart Study (Catarina). [citado 09 out. 2017]; Disponível em: https: / / www.clinicaltrials.gov/ct2/show / NCT03015064.

11. Sianos G, Morel M, Kappetein A, Morice MC, Colombo A, Dawkins K, et al. The SYNTAX score: an angiographic tool grading the complexity of coronary artery disease. EuroIntervention. 2005;1(2):219-27.

12. Gibson CM, Cannon CP, Daley WL, Dodge JT Jr, Alexander B Jr, Marble $\mathrm{SJ}$, et al. TIMI frame count : a quantitative method of assessing coronary artery flow. Circulation. 1996;93(5):879-88.

13. Escosteguy CC, Portela MC, Medronho RA, Vasconcellos MTL. Infarto agudo do miocárdio: perfil clínico-epidemiológico e fatores associados ao óbito hospitalar no município do Rio de Janeiro. Arq Bras Cardiol. 2003;80(6):593-9.

14. Araújo IFM, Santos ISC, Longuiniere ACF, Valença Neto PF, Franklin TA. Profile of the population affected by acute myocardial infarction. J Nurs. 2016;10(7):2302-9.

15. Mertins SM, Kolankiewicz ACB, Rosanelli CLSP, Loro MM, Poli G, Winkelmann ER, et al. Prevalence of risk factors in patients with acute myocardial infarction. Av Enferm. 2016;34(1):30-8.

16. Adhikari G, Baral D. Clinical profile of patients presenting with acute myocardial infarction. Int J Adv Med. 2018;5(2):228-33.

17. Martin LM, Januzzi JL, Thompson RW, Ferris TG, Singh JP, Bhambhani $\mathrm{V}$, et al. Clinical profile of acute myocardial infarction patients included in the hospital readmissions reduction program. J Am Heart Assoc. 2018;7(16):e009339.

18. Grassi D, Desideri G, Necozione S, di Giosia P, Barnabei R, Allegaert L, et al. Cocoa consumption dose-dependently improves flow-mediated dilation and arterial stiffness decreasing blood pressure in healthy individuals. J Hypertens. 2015;33(2):294-303. 
19. Rostami A, Khalili M, Haghighat N, Eghtesadi S, Shidfar F, Heidari I, et al. High-cocoa polyphenol-rich chocolate improves blood pressure in patients with diabetes and hypertension. ARYA Atheroscler. 2015;11(1):21-9.

20. Shah SR, Alweis R, Najim NI, Dharani AM, Jangda MA, Shahid M, et al. Use of dark chocolate for diabetic patients: a review of the literature and current evidence. J Community Hosp Intern Med Perspect. 2017;7(4):218-21.

21. Engler MB, Engler MM, Chen CY, Malloy MJ, Browne A, Chiu EY, et al. Flavonoid-rich dark chocolate improves endothelial function and increases plasma epicatechin concentrations in healthy adults. J Am Coll Nutr. 2004;23(3):197-204.

22. Fraga CG, Litterio MC, Prince PD, Calabró V, Piotrkowski B, Galleano M. Cocoa flavanols: effects on vascular nitric oxide and blood pressure. J Clin Biochem Nutr. 2011;48(1):63-7.

23. Desch S, Kobler D, Schmidt J, Sonnabend M, Adams V, Sareban M, et al. Low vs. higher-dose dark chocolate and blood pressure in cardiovascular high-risk patients. Am J Hypertens. 2010;23(6):694-700.

24. Irondi EA, Olanrewaju S, Oboh G, Olasupo F, Boligon AA. Inhibitory potential of cocoa leaves polyphenolics-rich extract on xanthine oxidase and angiotensin 1-converting enzyme. J Biol Act Prod Nat. 2017;7(1):39-51.

25. Bruinsma K, Taren DL. Chocolate: food or drug?. J Am Diet Assoc. 1999;99(10):1249-56.

26. Colombo G, Agabio R, Diaz G, Fà M, Lobina C, Reali R, et al. Sardinian alcohol-preferring rats prefer chocolate and sucrose over ethanol. Alcohol.1997;14(6):611-5.

27. Hetherington MM, MacDiarmid JI. "Chocolate addiction": a preliminary study of its description and its relationship to problem eating. Appetite. 1993;21(3):233-46.

28. Jager G, Witkamp RF. The endocannabinoid system and appetite: relevance for food reward. Nutr Res Rev. 2014;27(1):172-85.

29. Zendehdel M, Tirgari F, Shohre B, Deldar H, Hassanpour S. Involvement of gaba and cannabinoid receptors in central food intake regulation in neonatal layer chicks: role of CB1 and Gabaa receptors. Rev Bras Cienc Avic. 2017;19(2):221-9.
30. Asgary S, Rastgar A, Keshvari M. Functional food and cardiovascular disease prevention and treatment: a review. J Am Coll Nutr. 2018;37(5):429-55.

31. Matsumoto C, Petrone AB, Sesso HD, Gaziano JM, Djoussé L. Chocolate consumption and risk of diabetes mellitus in the Physicians' Health Study. Am J Clin Nutr. 2015;101(2):362-7.

32. Greenberg JA. Chocolate intake and diabetes risk. Clin Nutr. 2015;34(1):129-33.

33. Liu YJ, Zhan J, Liu XL, Wang Y, Ji J, He QQ. Dietary flavonoids intake and risk of type 2 diabetes: a meta-analysis of prospective cohort studies. Clin Nutr. 2014;33(1):59-63.

34. Hooper L, Kay C, Abdelhamid A, Kroon PA, Cohn JS, Rimm EB, et al. Effects of chocolate, cocoa, and flavan-3-ols on cardiovascular health: a systematic review and meta-analysis of randomized trials. Am J Clin Nutr. 2012;95(3):740-51.

35. Mastroiacovo D, Kwik-Uribe C, Grassi D, Necozione S, Raffaele A, Pistacchio L, et al. Cocoa flavanol consumption improves cognitive function, blood pressure control, and metabolic profile in elderly subjects: the Cocoa, Cognition, and Aging (CoCoA) Study--a randomized controlled trial. Am J Clin Nutr. 2015;101(3):538-48.

36. Ramos S, Martín MA, Goya L. Effects of cocoa antioxidants in type 2 diabetes mellitus. Antioxidants (Basel). 2017;6(4):pii:E84.

37. Magrone T, Russo MA, Jirillo E. Cocoa and dark chocolate polyphenols: from biology to clinical applications. Front Immunol. 2017 Jun 9;8:677.

38. Apostolidou C, Adamopoulos K, Lymperaki E, Iliadis S, Papapreponis P, Kourtidou-Papadeli C. Cardiovascular risk benefits from antioxidant dietary intervention with red wine in asymptomatic hypercholesterolemics. Clin Nutr ESPEN. 2015;10(6):e224-33.

39. Colombo AMJ, Valente Filho JM, Moreira DM. Effects of chocolate in the endothelial function of patients with acute coronary syndrome. Int J Cardiovasc Sci. 2015;28(2):89-94.

40. Duarte AAM, Mostarda C, Irigoyen MC, Rigatto K. A single dose of dark chocolate increases parasympathetic modulation and heart rate variability in healthy subjects. Rev Nutr. 2016;29(6):765-73. 